Bond University ePublications@bond

Sports Law eJournal

Faculty of Law

$11-12-2015$

\title{
Complex rules and inconsistent interpretation: Duty of care and causation in collision sports
}

Craig Dickson

Follow this and additional works at: http://epublications.bond.edu.au/slej

Part of the Entertainment, Arts, and Sports Law Commons

Recommended Citation

Craig Dickson. (2015) "Complex rules and inconsistent interpretation: Duty of care and causation in collision sports" „, : ISSN 1836-1129.

http://epublications.bond.edu.au/slej/29 


\title{
Complex rules and inconsistent interpretation: Duty of care and causation in collision sports
}

\begin{abstract}
In some sports, especially collision games such as rugby, well-intentioned rules, crafted to make the game safer, are being enforced as absolute liability offences. This article argues that an absence of fault stance should be adopted, to allow breaches of some safety rules to be adjudged as strict liability rather than absolute liability offences. If absolute liability is pursued regardless of fault, the coherence and welfare objectives of those safety rules are compromised. Indeed, the long-term viability of collision sports may become questionable.
\end{abstract}

\section{Keywords}

collision sports, contact sports, duty of care, absolute liability, rugby union, strict liability, All Blacks

\author{
Disciplines \\ Entertainment, Arts, and Sports Law | Law
}




\title{
DUTY OF CARE AND CAUSATION IN COLLISION SPORTS: COMPLEX RULES AND INCONSISTENT INTERPRETATION
}

\author{
CRAIG DICKSON*
}

\begin{abstract}
In some sports, especially collision games such as rugby, well-intentioned rules, crafted to make the game safer, are being enforced as absolute liability offences. This article argues that an absence of fault stance should be adopted, to allow breaches of some safety rules to be adjudged as strict liability rather than absolute liability offences. If absolute liability is pursued regardless of fault, the coherence and welfare objectives of those safety rules are compromised. Indeed, the long-term viability of collision sports may become questionable.
\end{abstract}

Developing skill levels, greater emphasis on player safety and the invasive impact of technology have all helped usher in progressively complex rule amendments to many sports - continuously complicating the adjudication of those sports. The litany of complaints over incorrect adjudication grows ever louder. ${ }^{1}$ Indeed, after a string of officiating blunders in the 2014 Rugby Championship, All Blacks' coach, Steve Hansen, suggested that the appropriate solution was to rip up the existing rule book and simplify the laws of rugby union by including only those rules that were 'necessary'. ${ }^{2}$ While a complete rewrite of the rule book may be excessive, many sporting codes have become quite convoluted - suffering from numerous ad hoc add-ons and intricate amendments at the expense of simplicity and clarity.

Often these rule amendments have been a response to the increasing use of technology in the adjudication of the game. ${ }^{3}$ There have also been a number of changes made to the rules of the socalled collision sports - the sports' governing bodies, appropriately, have instituted ever greater protections within the rules to try to increase the levels of safety of the participants. ${ }^{4}$ When such rules are poorly construed or misinterpreted, however, the integrity of the sport is damaged - an impact that is magnified when the rules intended to improve the welfare of the players are inconsistently applied.

Using incidents from the 2014 Rugby Championship, this article uses a fault-based, breach of duty of care reasoning borrowed from the tort of negligence to argue that, while entirely wellintentioned, game 'safety' rules cannot all be enforced as absolute liability offences. Unless an

* Senior Lecturer, Faculty of Business and Law, Auckland University of Technology, New Zealand. The author wishes to acknowledge Professor Allan Beever's assistance in the preparation of this paper.

1 Du Plessis red card 2013; penalty at end of Super 15 final, 2014; last wicket AUS v ENG, CWC 2015.

2 Otago Daily Times' article; ESPN article.

3 IRB TMO protocols.

4 Changes to engagement sequence in rugby union scrums (2007) 'Rugby \& rugby league tackle rules; modifications to hockey rules - hybrid icing since $2013^{\prime}<$ http://www.nhl.com/ice/news.htm?id $=684940>$.

@ 2015 the Author. Compilation@ @2015 Centre for Commercial Law Bond University. 
absence of fault rationale is properly implemented, thereby permitting breaches of some safety rules to be adjudged as strict liability offences, the coherence and welfare objectives of those rules are compromised. Furthermore, the long-term viability of collision sports becomes questionable.

Understanding this process requires the observation that the codified rules of most sports contain two fundamental elements. First are the purely 'game play' rules - those rules that determine the nature and substance of how participation in the game is to be carried out which includes outlines of such things as the field of play, allowable equipment, number of players along with the specifics of game play (eg in rugby union and rugby league the proscription against throwing or propelling the ball forward). Second, codified rules include what can be termed 'safety' or 'danger' rules - those rules that modify the application and potential outcome of the game play rules in order to try and safeguard player welfare to some degree as well as including proscriptions against violent conduct that is placed beyond the implied sanction of the participants. While voluntary participation in a contact sport generally involves consent to contact permitted under the express rules of the sport that might otherwise amount to assault, such participation also implies consent to those contacts which are not within the written rules of the sport but are nonetheless within the player's contemplation as a recognised part of that sport. However, greater appreciation of the risk of long term or the late onset of serious impairment resulting from some of the collisions that routinely occur in contact sports have led those sports' controlling bodies to modify the parameters of the scope of that implied consent. Latterly then, many sports have moved to outlaw acts that are seen to create 'unacceptable risks' of injury. Such modifications have had little impact on what can be termed 'game play' rules but have had great effect on 'danger rules' as initiatives to safeguard player welfare to a higher degree. Where previous breaches of the 'danger rules' have resulted in criminal prosecution and/or civil claims for the resulting injuries, the courts have been willing to consider the fact that a danger rule was breached (and the nature of that breach) as an entry point for determining liability, particularly where such a breach is indicative of non-consensual contact. Liability for breaches of safety rules should neither inhibit the vigorous participation of athletes nor diminish the attraction of the game for the spectators. By contrast, liability for breaches of game play rules (eg off side or icing) ${ }^{5}$ are nothing more than an impediment to the peaceful enjoyment of the game.

In the sporting arenas, actions such as physical contact on a playing field outside the rules of that particular game may give rise to both a civil action for trespass to the person, and/or a criminal charge for assault. Many of the sports cases that have resulted in criminal convictions could just as easily have involved civil litigation. Likewise, the cases which have involved a successful civil action are, in most instances, very similar in fact to cases involving a criminal charge.

However, the law must recognise as lawful certain, if not all, foul play which can be expected to occur during the course of a game. If force in sport is lawful because, not being intended or likely to cause harm, the consent of the participants is operative, then that is no different from the general rule which obtains about consensual violence. That still does not directly address though, those acts which while outside the rules (and often deemed 'foul play' by those rules), may still be considered part of the recognised (and accepted) incidents of that particular sport. Specifically, criminal or negligence liability for (for example) breaches of game play rules and the 'contemplated' outcomes of that breach requires an often nuanced investigation into elements such as the circumstances of the event, operative levels of implied consent, the intent of the actors involved and the seriousness of the consequent damage/injury. It is equally clear that

5 Usually resulting in a sanction or penalty that is prescribed within the rules of the game. 
stepping outside a 'danger rule' however, will often inherently result in some level of liability being imposed.

There is substantial jurisprudence to illustrate the point - albeit the cases have been decided under criminal provisions or as civil claims resulting from criminally sanctioned events within the game. Condon v Basi [1985] 1 WLR 866 is a 'soccer tackle' case where a foul tackle by the defendant during a game of soccer resulted in the plaintiff sustaining a fractured leg. The court concluded that the duty of care between players in competitive sports was a duty to take all reasonable care, taking into account the particular circumstances in which the competing players were placed.

Similarly, in Re Lenfield, ${ }^{6}$ the 13 year old plaintiff suffered severe injury inflicted during an informal game of rugby, when a 15-year-old boy of superior height and strength spear-tackled him into the ground. Higgins J took the view that whilst the tackle in question was executed for 'the primary reason of pursuing the proper objectives of the game' it was not 'a normal incident of it'. His Honour, focusing upon the relationship between breaches of safety rules and assault, stated:

It is well-known that in all football codes dangerous tackles are not permitted even if the motive of the tackler is to play the game rather than to injure the opposing player. It does not matter that dangerous tackles often happen. They are no less outside the rules for that if they are outside the rules and dangerous, they do not lose their character which they possess as unlawful assaults if deliberately or recklessly executed. ${ }^{7}$

A similar analysis was applied when Wests Tigers rugby league player, Jarrod McCracken received a career-ending neck injury after being spear-tackled by opposition players Kearney and Bai of the Melbourne Storm. ${ }^{8}$ Hulme J found the tackle was not carried out as 'normal incident of the game of rugby league'. In finding the Melbourne players and the club liable, his Honour focused on the 'inherent dangerousness of a player being upside down particularly when lifted' and considered the relevance of the rules of rugby league which 'recognise the danger and prohibit the event described as a dangerous throw', quoting from the relevant section of the Laws of the Game which describe it as such.

What Condon v Basi, Lenfield and McCracken demonstrate is that, in the case of contact sports, such as football and rugby, it will be almost impossible to establish liability unless the actions of the defendant are outside the rules of the game. Indeed the Court of Appeal (in Condon v Basi) appeared to be saying that a breach of the rules is virtually a necessary, albeit not a sufficient, requirement for liability to attach. Again, there is nothing special about sports cases in this regard - in various disciplines it has regularly been held that the rules and standards laid down by professional bodies provide a good guide as to the standards of reasonableness expected of those who operate in the fields governed thereby. Accordingly, a player acting outside those rules and standards will attract susceptibility to being found culpable (at certain levels) for any injurious outcome. $^{9}$

In short, not every foul will constitute a tort, but something short of a foul will not do so. Determination of the level of liability attaching to a particular act further requires investigation as

\footnotetext{
$6 \quad$ (1993) 114 FLR 195.

7 Ibid 197.

$8 \quad$ McCracken v Melbourne Storm Rugby League Club [2005] NSWSC 107.

9 Putting aside any defences (such as consent) which may be available.
} 
to whether greater culpability is appropriate where a claim results from a breach of a 'danger rule' (whether intentional or not) as compared with damage consequent on a breach of a game play rule.

'Borrowing' the language of the tort of negligence to facilitate this is apposite. That is, at what level do participants in sport owe each other a duty of care on the sports field? Very generally speaking, the tort of negligence has three main elements: the claimant must establish that the defendant (i) owed him a common law duty of care, (ii) breached that duty, and (iii) damage resulted. ${ }^{10}$

The primary aspect of the common law duty of care that is relevant to sport is the need to avoid foreseeable risks which result in foreseeable physical injury. That said, three main issues arise: first, whether there is a duty of care; second, if so, what standard of care is required; and third, where the claimant is a participant, whether and — if so - to what extent such voluntary participation provides a defence. The scope of the defence of consent lies outside the scope of this paper which will concentrate on the former elements: the substance of the duty of care owed and liability for breach of that duty on the field of play.

The existence of the duty of care element is easily satisfied - the codified rules of the game outline the duty owed by the player in respect of adherence to both the agreed game play rules and the danger rules: complete compliance, subject to the on-the-spot interpretation of the game officials as to the immediate ambit and scope of that compliance.

The substance of culpability resulting from a breach of that duty is then routinely adjudicated as requiring a determination that equates to the tortious standard of strict liability. That is, the common element to tortious claims in respect of a defendant who has not committed the act complained of either intentionally or negligently ${ }^{11}$ is that he may nevertheless be liable for the tort in certain circumstances. ${ }^{12}$ Often referred to as torts of 'strict liability', this terminology has been described as 'ambiguous' 13 and cannot be assigned a constant meaning - liability for all one's acts differs depending on the circumstances. ${ }^{14}$

However, a rule specifying strict liability makes a person legally responsible for the damage caused by their acts and omissions regardless of culpability. Under strict liability causa, not culpa, is paramount: liability follows from the occurrence of the damage at the defendant's hands, regardless of whether the defendant's behaviour was faulty ${ }^{15}$ - which is exactly the situation with respect to game play rules. A breach of a game rule results in the imposition of the penalty prescribed by the code: for a throw forward (which occurs when a player throws or passes the

10 Such a formulation by design, omits any detailed investigation into issues of causation and remoteness as well as any investigation of possible defences. Arguably, for the participants in a contact sporting contest, determination of issues of causation and foreseeability are usually straightforward. The existence (or otherwise) of consent as a defence will vary depending on the nature of the sport concerned, the rules under which it operates and the level to which any breaching of those rules is acceptably contemplated by the participants.

11 Ignoring circumstances involving potential vicarious liability where the defendant may be merely held accountable for the acts of an employee or independent contractor. Such situations are not relevant to the discussion of liability for sports persons acting within the field of play.

12 Brazier, 336.

13 Read v J Lyons \& Co [1947] AC 156, 171.

14 Brazier, above n 12.

15 Weinrib, 171. 
ball - 'towards the opposing team's dead ball line' at the extremity of the playing area), Law 12.1 of Rugby Union requires the non-offending team to acquire possession and the restart of the game with a scrum. That will be the case regardless of the intent of the player throwing or passing the ball forward. In fact, in almost all circumstances the player will be deliberately not intending to breach the rule ${ }^{16}$ - further highlighting the fundamental element of strict liability: liability will be imposed without a finding of fault and a claimant need only prove that the tort occurred and that the defendant was responsible.

Somewhat misleadingly, the imposition of strict liability is also sometimes referred to as 'absolute liability' suggesting that any defendant's liability is unchallengeable. ${ }^{17}$ In this context, absolute liability requires only an actus reus, whereas an act or omission may be excused even in strict liability where specific mitigating factors can be appropriately proved. The use of the terminology as synonyms tends to obscure more than it illuminates.

This division of liability ${ }^{18}$ is perhaps better outlined in the criminal context, where the two concepts are used less interchangeably than is the case in discussions in respect of liability in tort. When endorsing the requirement that for criminal liability to attach to an act the perpetrator must complete the specified actus reus while simultaneously possessing the necessary mens rea, the Senate Standing Committee for the Scrutiny of Bills further outlined the essentials of strict liability: ${ }^{19}$

An offence is one of strict liability where it provides for people to be punished for doing something, or failing to do something, whether or not they have a guilty intent. In other words, someone is held to be legally liable for their conduct irrespective of their moral responsibility. A person charged with a strict liability offence has recourse to a defence of mistake of fact.

While that reads very like the tortious prescription for strict liability, it does admit the possibility that there may be factors that allow for a defence to the imposition of liability. By contrast, an 'absolute liability' offence is one where the defence of mistake of fact is excluded, either expressly or by implication. ${ }^{20}$ In other words, the criminal law formulation is that absolute liability offences require only that the defendant perform the actus reus for the offence to be complete, whereas strict liability offences are the same except that a defendant may be able to escape liability if he can prove absence of fault. ${ }^{21}$

Arguably, such a construction of 'absolute liability' fully explains a breach of a game play rule. Breaches of game play rules are adjudicated as absolute liability offences and the sanction imposed regardless of intent. It is submitted however, that somewhat counterintuitively, breaches

16 It has to be noted however, that in cases where the match officials determine that the breach was intentional, different sanctions may apply. Law 12.1(f) outlines that for an intentional throw forward the 'punishment' is the award of a penalty kick to the opposing team.

17 Clerk \& Lindsell on Torts (20 edn) para 1-66 (pg 41).

18 Into 'absolute' and 'strict' elements.

19 Senate Standing Committee for the Scrutiny of Bills, Report of the Work of the Committee during the 39th Parliament (AUS), at para 2.97.

20 Government of NSW, Legislation Review Committee: Strict and Absolute Liability, Discussion Paper No 2 (8 June 2006), at para 18.

21 This seems to indicate also that strict liability in the criminal law is actually a fault standard, but where the fault is presumed unless demonstrated otherwise. The tort of negligence, in contrast, requires demonstration of all the elements of the tort before the existence and level of fault (and hence liability) can be determined. 
of 'danger rules' are not conducive to similar absolute liability enforcement particularly when the sanctions are imposed inconsistently.

A case in point is the wording and adjudication of Law 10.4 (Dangerous Play and Misconduct) in the Laws of Rugby Union. ${ }^{22}$ A 'tackle' in rugby union is elsewhere defined in the Laws as occurring 'when the ball carrier is held by one or more opponents and is brought to ground'. ${ }^{23}$ Law 10.4(e) proscribes 'early, late or dangerous' tackling, with the time issues relating to whether or not the tackled player is in possession of the ball when the tackle occurs. Among the various iterations of a dangerous tackle the Law stipulates that 'a tackle around the opponent's neck or head is dangerous play,' which will attract liability and the sanction of a penalty kick. Since the Law was initially so worded (and to remove any doubt as to the outcome in the interests of player welfare) the substance of the offence was updated in $2009^{24}$ to include:

A player must not tackle (or try to tackle) an opponent above the line of the shoulders even if the tackle starts below the line of the shoulders.

Accordingly, situations where the tackler even inadvertently makes contact with the opponent's head while tackling (or trying to tackle him) - as where the arms may slip up above the line of the shoulders - are now expressly included in the offence. Subjective intention and absence of fault not amounting to negligence are also to be sanctioned. It is still not clear, however, that adjudication of the amended rule as an absolute liability offence furthers the objectives of the player welfare intentions of the rule and, in fact, may compromise the integrity of the game play rule which it modifies. That is, although mistake of fact is not relevant in the sporting context, where there is no allowable mitigation of the liability of a rule such as the one under review, the continued playing of a contact sport is compromised. For example, if all instances of contact above the shoulders, however occurring, in all actual and potential tackle situations are prohibited (which is what the above rule seems to be contemplating) then the game of rugby union will likely be changed beyond recognition. It is submitted that (continuing the language of fault used in tortious claims), unless some absence of fault analysis can be used to inform the adjudication of 'danger rules' and therefore, ensure they are imposed as strict and not absolute liability offences, the coherence of game play in collision sports may require re-examination.

\section{EXAmple 1: Australia v Argentina, 4 OCTOBER 2014}

Practical examples of these principles in action were provided by two separate incidents that occurred during matches played as part of the 2014 Rugby Championship. ${ }^{25}$

During the course of Argentina's first victory in the Rugby Championship, the Australian fullback, Israel Folau, was penalised and initially sent from the field under the sanction of a yellow card. ${ }^{26}$

22 Note that, although these rules are clearly designed with player safety and welfare in mind, they appear to have been originally written to prohibit certain acts deemed dangerous, thereby placing those acts outside the acceptable boundaries of game play. In fact, these rules are still classified as such with the overall section title of 'Method of Playing the Match.'

23 Law 15. 'Brought to ground' is further defined in Law 15.3 variously as including having 'one or both knees on the ground', 'sitting', or 'on top of another player on the ground'.

24 See http://www.rugbyfootballhistory.com/laws.htm.

25 The annual four nations, southern hemisphere tournament that includes games between New Zealand, Australia, South Africa and Argentina.

26 Law 10.5(a). 
At around 57 min 30 secs running time, Folau was presumably determined to have transgressed Law 10.4(i), which relevantly reads: ${ }^{27}$

A player must not tackle nor tap, push or pull the foot or feet of an opponent jumping for the ball $\ldots$ in open play.

The circumstances disclose that, in following a deflected kick in an attempt to retrieve the ball, Folau collided with the Argentine fullback, Joaquín Tuculet, who had jumped to catch the ball and was in the air at the time of the collision. Folau was bent over at the time of the contact which was made on Tuculet's hip from Folau's shoulder, causing Tuculet to fall heavily to the ground. The referee immediately halted play, awarded a penalty to Argentina, and ordered Folau from the field to complete the required ten minute suspension for a violation of a provision of Law 10.

Having viewed a replay of the incident on the large screen at the ground, however, the referee, Nigel Owens rescinded the suspension and allowed Folau immediately to return to the field of play. ${ }^{28}$ What the video footage revealed was that prior to making contact with Tuculet, Folau appeared to pull up, but was then propelled towards Tuculet either because he had been pushed by the Argentine no 13, Horacio Agulla, or had stumbled after coming into contact with both Agulla and another Argentine player (No 11, Lucas González Amorosino). The former scenario was apparently what Owens thought had happened, because he explained the fact of a push to the Argentine captain and reversed the award of the penalty. Bizarrely, however, the game then restarted with Argentina taking the penalty kick without further explanation, although after the referee had again viewed the video replay.

These events appear to indicate that the referee was alive to the possibility of absence of fault in the outcome. Having initially deemed Folau to be responsible for the prohibited contact, the sanction was imposed on absolute liability principles. Without recourse to any mitigation, Folau was held liable for the breach of the rule and penalised accordingly. However, on video review of the incident, ${ }^{29}$ the referee in the first instance rescinded the sanction - explaining that the 'breach' of the rules was the result of a push by another. ${ }^{30}$ It appears that Folau's subjective intention may have had some impact on this rationale, but the much maligned 'but for' test of causation also seems to have played a determinative role. Absent the push by Agulla, Folau would not have not made contact with Tuculet, ${ }^{31}$ and, where there was no subjective intention to breach the rule,

27 Folau may also have transgressed a provision of Law 10.4(e): 'A player must not tackle an opponent whose feet are off the ground' but nothing turns on that for the purposes of this analysis.

28 Although an unusual occurrence this reversal of a sanction is in line with the newly promulgated law revision entitling any match official to use video replay in order to clarify sanctions required for acts of foul play (Law 6.A.7(b)(vi) and entirely in line with Law 6.A.4(a): 'The referee is the sole judge of fact and of Law during a match.'

29 Which should probably be seen as a commendable use of the 'best evidence' available principles.

30 The push on Folau by the opposition player was a clear breach of the game play rule, Law 10.4(f): 'a player who is not in possession of the ball must not hold, push or obstruct an opponent not carrying the ball.'

31 It is submitted that this analysis also holds even where the contact between Folau and the two Argentine players was wholly accidental. The contact and resulting stumble was the operative ('but for') cause for which Folau is still not culpable. Accidental contact would mean however, that no sanction could be levied on any of the players - which could in any event, be the outcome if the defence of consent is raised. That is, the accidental contact and the outcome fall within the parameters of contact voluntarily consented to by the participants. 
absence of fault by Folau mitigates the imposition of liability for any sanction. The initial absolute liability adjudication is correctly amended to a strict liability determination and the culpability for the event reassigned. Why the consequent reversal of the penalty, as originally contemplated, was not effected remains puzzling.

\section{EXAMPLE 2: NEW ZEALAND v SOUTH AFRICA, 4 OCTOBER 2014}

International matches between traditional rivals, New Zealand and South Africa, are usually very close encounters. The final contest between the teams at the 2014 Rugby Championship was no exception. At the time of the incident in question, New Zealand held a one point lead with barely three minutes left to play. The South African player, Schalk Burger, was in possession moving laterally in centre field. As he approached the New Zealand defensive line at speed, the New Zealand player, Liam Messam prepared to tackle Burger more or less head on. Before that occurred, Burger was tackled from the side by another New Zealand Player, Dane Coles causing him (Burger) to fall forwards and into Messam. At the same instant Messam was beginning the drive with this shoulder that would initiate the contact of a tackle as a precursor to wrapping his arms around the South African to effect the tackle. As Burger fell and Messam moved forward, however, Burger's head came into contact with Messam's shoulder and Messam's arms swung around, ${ }^{32}$ unable to make any other contact with his opponent. Burger went to ground in Cole's tackle, South Africa recycled the ball and play continued uninterrupted for more than 30 seconds and some 30 metres upfield before being halted by the referee, Wayne Barnes.

At that time (while play was suspended), the TV broadcasters chose to show slow motion footage of the incident, which broadcast is viewable within the stadium. The playing of the video footage generated a vociferous reaction from the crowd and the referee was alerted to the incident by the South African captain, Jean de Villiers (presumably after he had also seen the footage on the screen in the stadium). As a consequence, Barnes asked the Television Match Official (TMO) ${ }^{33}$ if there was something he should look at?'34 The referee then viewed the incident a number of times and determined that the 'tackle' was a breach of the dangerous tackling rules, awarding South Africa a penalty from which the team scored the winning points.

Barnes variously explained that, 'although [Burger] was falling [Messam] still made contact with the head' and although there was 'nothing intentional [Messam] still caught him high', which meant that the action had to be sanctioned.

32 Some commentators have argued that Messam's actions were in fact, indicative of a so-called swinging arm tackle which is proscribed by the rules as dangerous play: Law 10.4(e). See for example, http://ratetheref.co.za/2014/10/06/kaplans-comments-rugby-championship-round-6/. It is submitted that given the nature and speed of the collision that is a subjective interpretation that is merely as plausible as the alternative outline provided.

33 A match official empowered under Law 6.A. 7(b) to use 'technological devices to clarify [certain] situations'.

34 It needs to be noted that the sequence of events seems to show that the clarification and subsequent adjudication of the incident was initiated by the decisions of the local TV broadcaster and the consequent crowd reaction. This episode therefore, also raises questions fundamental to the decisionmaking process on the field - especially as the incident in question occurred within meters of the referee on the field and was otherwise not highlighted by any match official prior to the in-stadium broadcast. 
This seems to indicate that notwithstanding the subjective interpretation of the use of the arms in the tackle, ${ }^{35}$ Barnes construed the actions of Messam as amounting to an absolute liability offence. That is even in the absence of intention, any contact with the head would be considered an offence. Arguably, that may only be in the immediate circumstances of a tackle but it is not clear that was the situation in this match. Recall that a tackle is defined as "when the ball carrier is held by one or more opponents and is brought to ground' and the rules proscribe tackling (or trying to tackle) an opponent 'above the line of the shoulders even if the tackle starts below the line of the shoulders'. Strictly construed in the current circumstances, Messam did not effect a tackle and it is questionable whether he was trying to tackle above the line of the shoulders. ${ }^{36}$ Moreover, as the only point of contact was head to shoulder the proviso to the rule cannot be operative either.

Perhaps more importantly, it seems more than likely that 'but for' the outcome of the tackle by Coles (ie Burger falling), Messam would not have made the contact that was sanctioned. Furthermore, without a clear breach of Law 10.4 it is not obvious that in circumstances 'surrounding' tackles that any contact with the head should be adjudicated as an absolute liability offence. For example, should Burger have fallen more quickly than he did and his head contacted Messam's hip or knee, it is doubtful that any further notice would have been taken of the incident ${ }^{37}$ and certainly no sanction imposed, unless intent was obvious? These latter circumstances would doubtless lead the incident to be determined as accidental contact and certainly within the contemplation of the participants as contact impliedly consented to, even if outside the rules.

In defence of the integrity of adjudication in contact sporting contests, it is helpful to distinguish between purely game play rules and those rules that exist or have been developed to maximise player safety - the 'danger rules'. Such rules have properly been modified and strengthened as greater knowledge, particularly in respect of long-term player welfare has been amassed. However, it is not clear that it remains appropriate to adjudicate these two types of rules in the same way and to do so may even damage the integrity (and continuing viability) of the sport.

Using the terminology of tort law to investigate this issue, the substance of the relevant rule breach can be identified as resulting in either absolute liability or strict liability for the offence. That terminology can often be used interchangeably in tortious claims, whereas in the criminal law the difference between the two types of culpability is better highlighted. Absolute liability results where the offence is complete once the actus reus is fulfilled and no mental element is required. By contrast, strict liability offences similarly require the accomplishment of the actus reus but admit of some mitigation (such as absence of fault) to operate as at least a partial defence. While the former is an appropriate way to adjudicate in respect of game play rules, it is submitted that danger rules can only be strict liability offences.

Putting aside issues of (implied) consent, inquiry into the substance of the danger rules (again utilising the terminology of tort law) shows that the duty of care owed by the players to each is other is manifest in the agreed rules. That inquiry also reveals that resolving of issues of causation

35 Which would probably not on its own, amount to a sanctionable offence in the current circumstances. See also the discussion infra, ff. 25.

36 Front on tackles are difficult to execute, particularly high up on an opponent's body. In any event, player statistics show that Burger is some $4 \mathrm{~cm}(1 \mathrm{inch})$ taller that Messam, meaning that if both players were upright at the time of contact, a point of contact above the shoulders is unlikely.

37 Unless of course, injury resulted from would almost certainly have been considered accidental contact. 
and remoteness are straightforward but the coherence of the rules is enhanced where a strict liability enforcement regime is employed. It is not clear that absolute liability sanctions under danger rules enhance the welfare objectives of those rules. Moreover, if every breach of a danger rule attracted a sanction on the fulfilment of the actus reus of the rule, a great number of the collisions consequent on the playing of contact sports would be proscribed - a result that further damages the integrity of the sport when the available sanctions are inconsistently applied.

The two highlighted incidents from the 2014 Rugby Championship illustrate these elements. The Folau incident was clearly the result of a chain of causation and 'but for' contact outside of the rules for which he was not culpable, Folau would not have breached the relevant danger rule. The circumstances in the Messam incident may be less clear cut but similarly, the chain of causation and the ambit of the allegedly breached rule demonstrate that 'but for' other events ${ }^{38}$ Messam was unlikely to have breached the danger rule. In both cases, it is arguable that the actions of the two players sanctioned should have been exempted under the absence of fault rationale. Yet that similar state of affairs resulted it two quite different outcomes. Folau's actions were initially sanctioned under absolute liability principles but ultimately excused once an absence of fault rationale was employed.

The incident involving Messam, however, seemed to be entirely determined as an absolute liability offence with any lack of intention not operating to mitigate the situation. Even where the relevant rule expressly includes some elements of inadvertence as sanctionable, it is not clear that absence of fault should be entirely excluded. Given that in similar circumstances contacting an opponent's head (ie above the shoulders) with other parts of the body would not result in a penalty, the player welfare objective of the rule is not maximised by adjudication of it as an absolute liability regulation. It is submitted that some absence of fault must be available even for 'danger rules' as otherwise all collisions outside the rules would be automatically considered offences, even where they may clearly be contemplated ${ }^{39}$ by the sports' participants. Should such a rationale be taken to its logical conclusion, the substance of many of the collisions fundamental to the operation of contact sports would be compromised and those sports changed irrevocably. The fact that similar incidents should be adjudicated quite differently across games in the same tournament also goes to the integrity of the enforcement of that sport's rules which further highlights the danger of inappropriate determination of what should only be strict liability offences (in the absence of wording to the contrary).

38 In this case action within the rules, ie Coles' tackle on Burger.

39 Therefore, also impliedly consented to. 